\title{
MODIFIED COOPERATIVE ACCESS WITH RELAY'S DATA PROTOCOL USING SMART ANTENNA
}

\author{
Ahmed Magdy *, S. Sayed and K. R. Mahmoud \\ Staff in Communication and Computer, Faculty of Engineering Helwan University, Cairo, Egypt
}

Received 28 February 2013; accepted 20 July 2013

\begin{abstract}
In this paper, a new protocol named Modified Cooperative Access with Relay's Data (MCARD) for wireless local area networks is proposed. MCARD gives remote stations chance to send their information by using intermediate stations (relays) to Access Point. In the MCARD, a relay and source stations send their information simultaneously to the access point and relay station, respectively, using a smart antenna technique. A uniform circular array of 12 half-wave dipole antenna elements is considered to control the array beam-forming of both relay and source stations. Analytical and simulation results show that MCARD can significantly improve system quality of service (QOS) in terms of throughput and delay under ideal channel conditions.
\end{abstract}

Keywords: cooperative communication, MAC, UCA, WLAN.

\section{Introduction}

IEEE 802.11 Wireless Local Area Network (WLAN) standards [1-4] have been globally accepted and adopted to provide wireless broadband access services in office, home and city hotspot areas. They can support multiple transmission data rates according to the channel conditions between wireless stations and Access Point (AP). For example, the IEEE 802.11b WLAN [2] supports the data-rates of 11, 5.5, 2 and $1 \mathrm{Mbps}$ to the AP. Low data rate stations have negative effects on the performance of the overall throughput in the network. Over the shared communication channel, these stations take longer time to transmit fixed packet to the AP compared to the high data rate stations. Therefore, the overall system performance is degraded [5].

The concept of cooperative communication is considered in the literature to improve link capacity, transmission reliability and network coverage in multiuser wireless communication networks[6-13].In which, multiple stations in a wireless network coordinate their packet transmissions and share each other's resources. In [14-21] a source node with low data-rate uses a neighboring high data rate station as a relay to forward its information to the AP considering only omnidirectional antenna. As a result, the other nodes have to wait until the source node's transmission is completed affecting negatively on the system performance. However, the performance can be improved when the shared channel is occupied with more than one transmission from different nodes at the same time. This can be achieved by using smart antenna techniques [22-23].

Smart antenna arrays with adaptive beam-forming capability are found to be very effective in the suppression of interference and multipath signals. The techniques of placing nulls in the antenna patterns to suppress interference and maximizing their gain in the direction of desired signal have received considerable attention in the past and are still of great interest using evolutionary algorithms such as genetic algorithms (GA) and

Corresponding author.

E-mail address: eng_ahmedmagdy86@yahoo.com 
Ahmed Magdy, et al., Modified Cooperative Access with Relay's Data (MCARD) Protocol, pp. 2231 - 2243

Particle Swarm Optimization (PSO)[24-25]. Recently, the Gravitational search algorithm (GSA) is a new optimization technique based on the law of gravity and mass interaction [26] is considered. A set of various problems were examined and in most cases the GSA provided superior or at least comparable results with Real Genetic Algorithm (RGA) and PSO [27].

Different smart antenna array geometries are proposed including mainly uniform linear arrays (ULA) and uniform circular arrays (UCA). It is found that, the ULA does not work equally well in all azimuthal directions. However, the UCA geometry can be electronically rotated in the plane of the array without a significant change of the beam shape [28].

In this paper, a new protocol named Modified Cooperative Access with Relay's Data (MCARD) for wireless local area networks based on smart antenna system is proposed. This protocol takes the advantages of both cooperative communication and smart antenna techniques optimized using the GSA. A low data-rate station, source node, sends its information to the AP through a high data-rate node, a relay node. In addition, the relay node sends its own information to the AP at the same time of receiving the information from the source node. Therefore, the system performance can be highly improved by using smart antenna techniques and the concept of cooperative communication.

The reminder of paper is organized as follows. Section 2 presents the signal model, the design of antenna and the estimation of steering problem. Section 3 introduces the system model and the proposed MCARD protocol. The analytical model of the proposed MCARD protocol is given in Section 4. Analytical and simulation results are presented and discussed in Section 5, followed by conclusions in Section 6.

\section{System Model}

In this research a multi-rate WLAN IEEE $802.11 \mathrm{~b}$ is considered. The IEEE $802.11 \mathrm{~b}$ supports data rates 1, 2, 5.5, and $11 \mathrm{Mbps}$. As shown in Fig.1, a source station with low data-rate sends its information to the AP through a high-data rate relay station to improve its communication performance with the AP. A low data-rate source station continuously evaluates its high data-rate neighboring stations and selects the best one as its potential relay station. The source station makes decision to use direct or cooperative link based on the following equation.

$$
\text { weight }=\frac{1}{\mathrm{R}_{\mathrm{ad}}}-\left(\frac{1}{\mathrm{R}_{\mathrm{ax}}}+\frac{1}{\mathrm{R}_{\mathrm{rd}}}\right)
$$

where $\mathrm{R}_{\mathrm{gd}}, \mathrm{R}_{\mathrm{gy}}$ and $\mathrm{R}_{\mathrm{rd}}$ stand for source-AP data-rate, Source-Relay data-rate, and Relay-AP data-rate, respectively. In addition, the antennas of both source and relay stations are designed based on the concept of smart antenna technology. A smart antenna array consists of $\mathrm{M}$ identical elements that can maximize the signal toward desired directions while minimizing the signals toward other directions. For adaptive array of UCA using space division multiple access (SDMA), the optimal radiation patterns design of smart antennas of both source and relay stations are developed based on the Gravitational Search Algorithm (GSA) technique. The AP antenna is assumed to be omnidirectional.

Journal of Engineering Sciences, Assiut University, Faculty of Engineering, Vol. 41, No. 6, November, 2013, E-mail address: jes@aun.edu.eg 


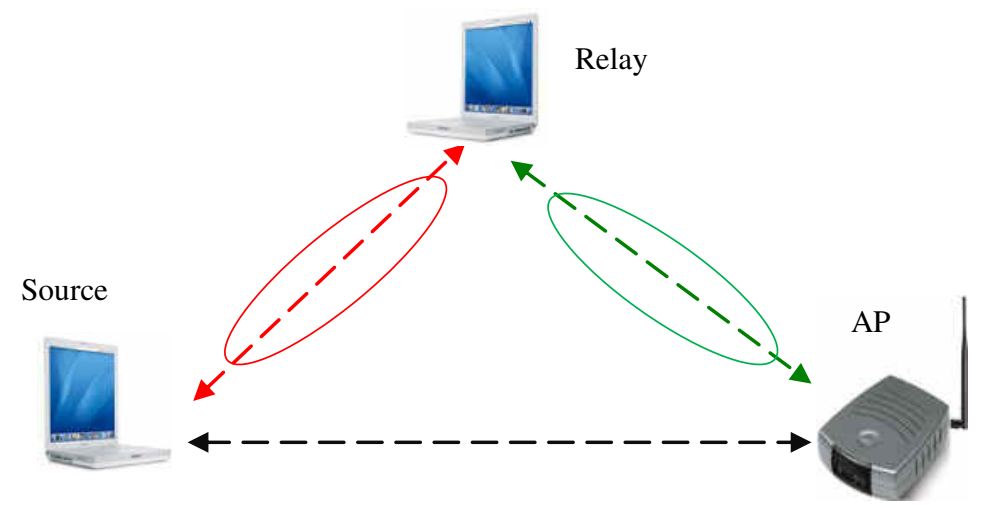

Fig. 1. System Model

\section{The MCARD Algorithm}

The proposed MCARD protocol supports two transmission modes. If a relay node is available, the source node sends its information cooperatively; otherwise the source node sends its information directly to the AP. As shown in Fig. 2 under cooperative transmission, the source node sends a cooperative RTS (CRTS) packet omnidirectionally to both AP and relay. Upon receiving the CRTS, the AP replies with CTS omnidirectionally to the source and relay nodes after short inter-frame space (SIFS). If a Relay CTS (RCTS) packet from the relay node is successfully received at the right time instant, the source node sends its data packetat at the data-rate $\mathrm{R}_{\operatorname{sx}}$ using directional beam pattern to only the relay node. The relay node sends its own data packet using also directional beam pattern to the AP and receives from the source node at the same time. Then, the relay node sends the source's data packet to the AP at the data-rate ${ }^{R_{\text {rd }}}$ after finishing the transmission of its own data packet. If the AP receives the data packet from either source or relay nodes or both; the AP sends a Cooperative ACK (CACK) packet.

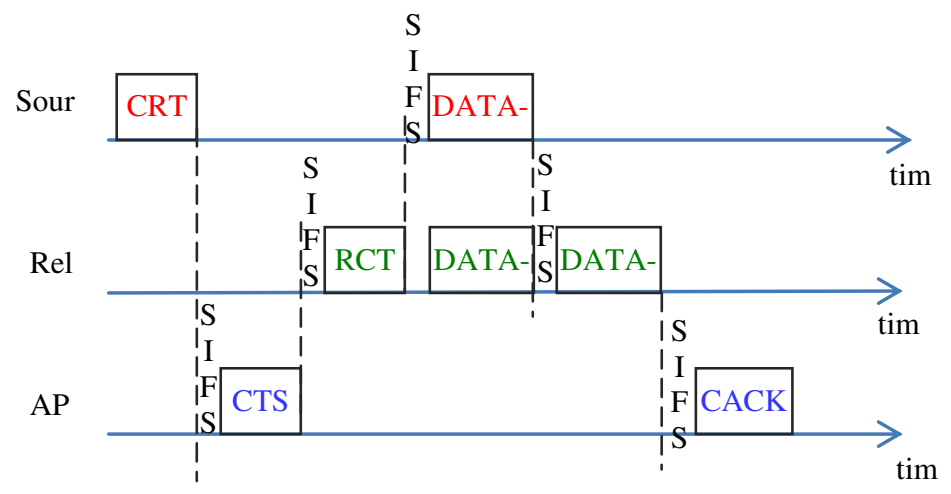

Fig. 2. Transmission under cooperative communication

If the relay node is not ready to cooperate, the source node sends it data packet directly to the AP after receiving the CTS packet as shown in Fig. 3. The AP replies with ACK packet when the data packet from the source node is received correctly.

Journal of Engineering Sciences, Assiut University, Faculty of Engineering, Vol. 41, No. 6, November, 2013, E-mail address: jes@aun.edu.eg 


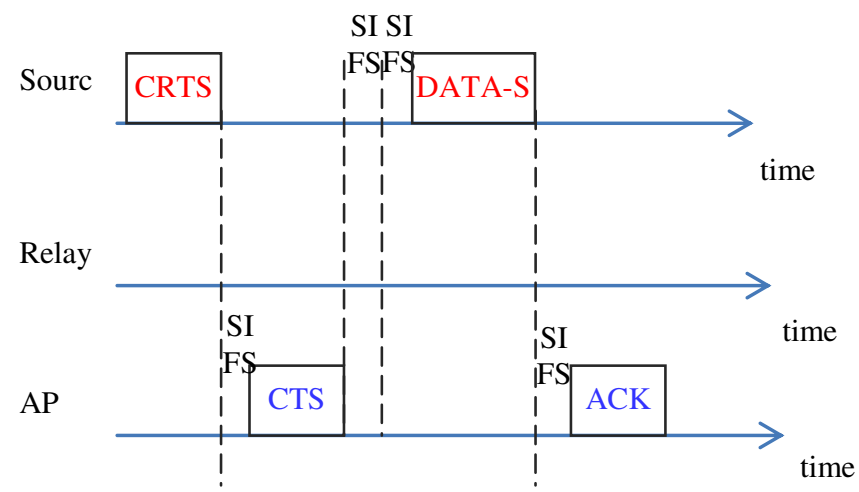

Fig. 3. transmission under noncooperative communication (direct)

\section{Smart Antenna Array Beam-Forming}

To achieve the desired goals of the proposed MCARD to transmit directionally from the source to the relay and from the relay to the AP simultaneously, an antenna array is proposed. The array structure consists of Misotropic elements uniformly distributed along the perimeter of a circle of radius ${ }^{r}$ as shown in Fig.4.

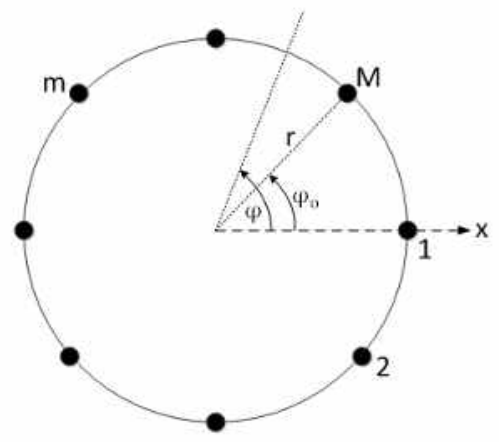

Fig. 4. Geometry of the UCA with $M$ elements.

For beam-forming synthesis, the feeding of each antenna element (amplitude and phase) needs to be optimized to maximize the main-lobe to certain directions. In this study the Gravitational Search Algorithm (GSA) is proposed to synthesize the beam-pattern by optimizing the antenna feeding parameters. GSA is based on the law of gravity and mass interaction [15]. The algorithm considers agents as objects consisting of different masses.

Each agent in GSA is specified by four parameters: position of the mass in ${ }^{d^{\text {th }}}$ dimension, inertia mass, active gravitational mass and passive gravitational mass. The positions of the mass of an agent at specified dimensions represent a solution of the problem and the inertia mass of an agent reflects its resistance to make its movement slow. Both the gravitational mass and the inertial mass, which control the velocity of an agent in specified dimension, are computed by fitness evolution of the problem, the positions of the agents in specified

Journal of Engineering Sciences, Assiut University, Faculty of Engineering, Vol. 41, No. 6, November, 2013,E-mail address: jes@aun.edu.eg 
Ahmed Magdy, et al., Modified Cooperative Access with Relay's Data (MCARD) Protocol, pp. 2231 - 2243 dimensions (solutions) are updated every iteration and the best fitness along with its corresponding agent is stored. The principle of GSA is shown in Error! Reference source not found.5, and more details are listed in [26].

The quality of an antenna beam-forming is expressed mathematically by an objective function which represents the interface between the physical problem and the optimization algorithm. In general, the objective function could be the antenna gain, directivity, SLL, or some kind of weighted sum of all these factors. Therefore, The following objective function rewards the antenna array for maximizing the output power toward the desired signal at $\varphi_{i}$.

Objective function $=\sum_{\mathrm{i}=1}^{\mathrm{N}} \mathrm{a}_{\mathrm{i}} \mathrm{AF}\left(\varphi_{\mathrm{i}}\right)$

where $\operatorname{AF(\varphi _{i})}$ is the antenna array factor at angle ${ }^{\varphi_{i}}$ (desired node direction) and the constant ${ }^{\mathrm{a}_{\mathrm{i}}}$ is the weight of the $\mathrm{i}^{\text {th }}$ desired direction that controls the priority of maximizing the power to a certain direction rather than others. In this paper, the source desired direction is the relay node position. Whereas the relay node has two desired directions, one direction to receive from the source and the other direction to send to the AP as shown in Fig. 1.

\section{Performance Evaluation}

\section{1. Markov chain model}

In [20-21], Markov chain model is proposed. A two-dimensional Markov chain model shown in Fig. 6 and consider the frame retry limits. Two parameters, backoff stage and backoff counter value, are used to describe the state of an IEEE 802.11b node. The pair (backoff stage, backoff counter value), referred to as (i, k), describes the state of a node. The backoff stage, i, starts at 0 at the first attempt to transmit a packet and is increased by 1 every time a transmission attempt results in a collision, up to a maximum value $\mathrm{m}$. The counter $\mathrm{k}$ is initially chosen uniformly between $[0, \mathrm{Wi}-1]$ where typically $\mathrm{Wi}$ is the range of the counter. The probability of transmitted packet from node $i$ is unsuccessful due to a collision transmission. Let $\tau \mathrm{i}$ be the probability that the node $\mathrm{i}$ transmits during a randomly chosen slot time and ${ }^{\mathrm{P}_{\mathrm{c}, \mathrm{i}}}$ the collision probability.

Journal of Engineering Sciences, Assiut University, Faculty of Engineering, Vol. 41, No. 6, November, 2013, E-mail address: jes@aun.edu.eg 


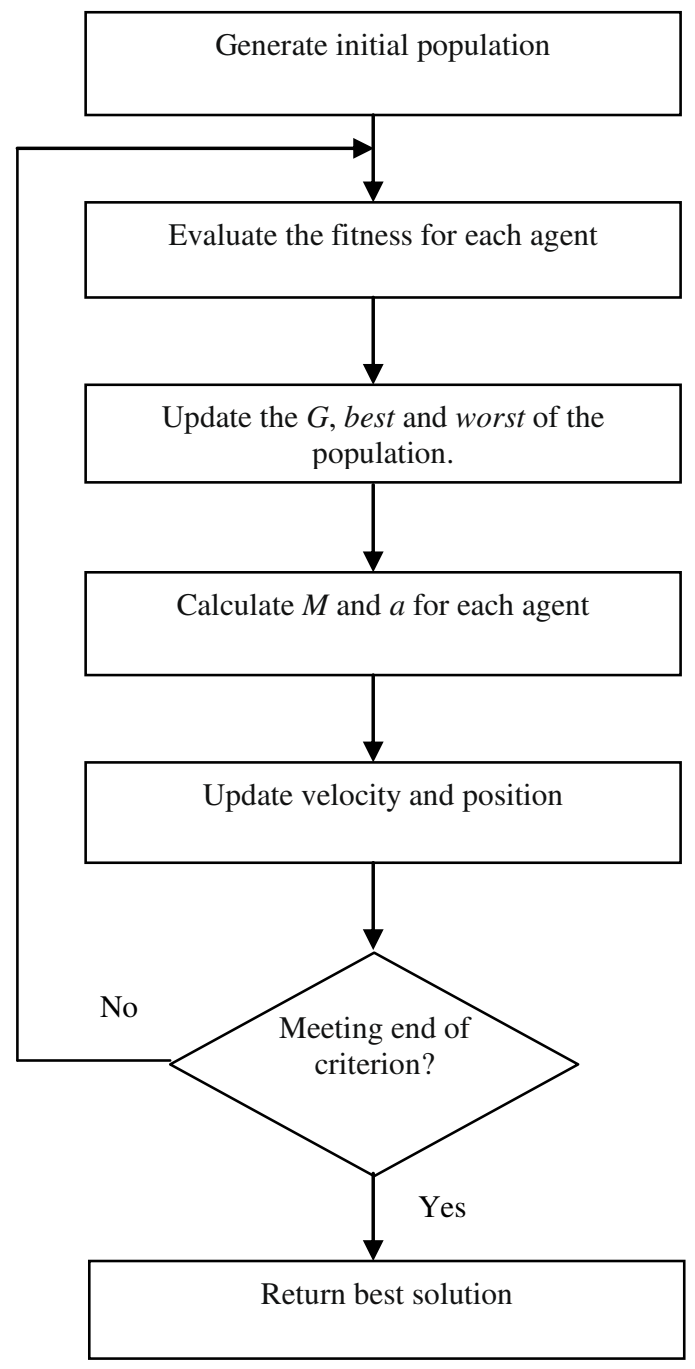

Fig. 5. Flow Chart of GSA

The node accesses the medium when its backoff counter reaches zero, regardless of the backoff stage. $\tau$ i can be calculated in [21,22]. Another modification in MCARD in the successful transmission period for two-hop transmission as shown:

$$
\begin{aligned}
\mathrm{T}_{\mathrm{S}, \mathrm{i}}^{\mathrm{C}}=\mathrm{T}_{\text {CRTS }}+ & \mathrm{T}_{\text {CCTS }}+\mathrm{T}_{\text {RRTS }}+\frac{8 \mathrm{~L}}{\mathrm{R}_{\mathrm{gd}}} \mathrm{I}(\mathrm{X})+\frac{8 \mathrm{~L}}{\mathrm{R}_{\mathrm{rd}}}(1-\mathrm{I}(\mathrm{X}))+\frac{8 \mathrm{~L}}{\mathrm{R}_{\mathrm{rd}}}+2 \mathrm{~T}_{\text {PLCP }} \\
& +5 \mathrm{~T}_{\text {SIFS }}+\mathrm{T}_{\text {CACK }}+\mathrm{T}_{\text {DIFS }}+68
\end{aligned}
$$

Finally, given the set of these equations, a non-linear system can be solved to determine $P_{C}$ (collision probability) and $\tau \mathrm{i}(\forall \mathrm{i}=1,2, \ldots, \mathrm{N})$. Therefore, in the following sections, we can then derive the system throughput.

Journal of Engineering Sciences, Assiut University, Faculty of Engineering, Vol. 41, No. 6, November, 2013, E-mail address: jes@aun.edu.eg 


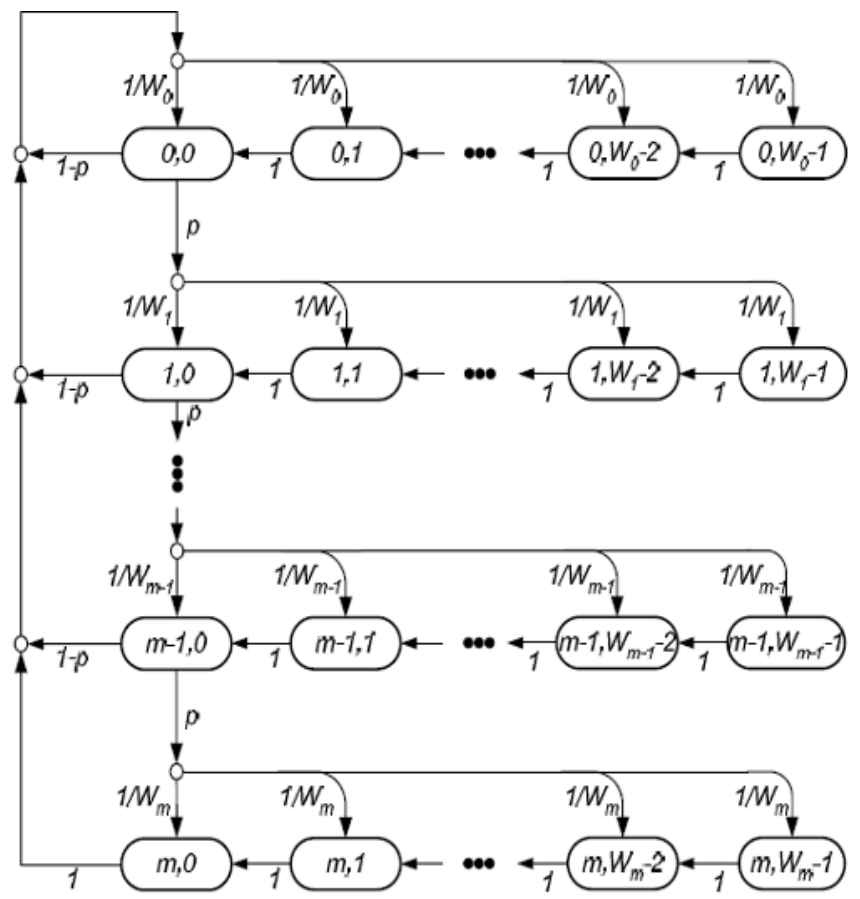

Fig. 6. Markov chain model

\section{2. Throughput}

In this section, an expression for the saturated throughput of MCARD protocol is presented. The saturated throughput $\mathrm{S}$ is defined as a ratio of successfully transmitted payload size over a randomly chosen slot time duration:

$$
\mathrm{S}=\frac{\mathrm{E}[\mathrm{PL}]}{\mathrm{E}\left[\mathrm{T}_{V}\right]+\mathrm{E}\left[\mathrm{T}_{v}\right]+\mathrm{E}\left[\mathrm{T}_{S}\right]}
$$

where $\mathrm{E}[\mathrm{PL}]$ is the average payload size, ${ }^{\mathrm{E}}\left[\mathrm{T}_{F}\right]$ is the average idle slot duration, $\mathrm{E}\left[\mathrm{T}_{\mathbb{E}}\right]$ is the average collision slot duration, and ${ }^{\mathrm{E}}\left[\mathrm{T}_{S}\right]$ is the average successful transmission slot duration.

Given the slot time size $\sigma$ and the probability that there is at least one node transmitting in the considered time slot is ${ }^{\mathrm{P}_{\text {trr }}}$, we get:

$$
\begin{aligned}
& \mathrm{E}\left[\mathrm{T}_{I}\right]=\left(1-\mathrm{P} \operatorname{tr}^{2}\right) \sigma \\
& \mathrm{E}\left[\mathrm{T}_{d}\right]=\mathrm{P}_{\mathrm{c}}^{\mathrm{d}} \mathrm{T}_{\mathrm{c}}^{\mathrm{d}}+\mathrm{P}_{\mathrm{c}}^{\mathrm{c}} \mathrm{T}_{\mathrm{c}}^{\mathrm{c}}
\end{aligned}
$$

where, ${ }^{P_{c}^{d}}$ is collision probability in direct transmission, ${ }^{P_{c}^{c}}$ is collision probability in cooperative transmission, ${ }^{\mathrm{d}}$ and $\mathrm{T}_{\mathrm{c}}^{\mathrm{c}}$ are collision time in direct and cooperative transmission, respectively.

$$
\mathrm{E}\left[\mathrm{T}_{S}\right]=\mathrm{E}\left[\mathrm{T}_{\mathrm{a}}^{\mathrm{d}}\right]+\mathrm{E}\left[\mathrm{T}_{\mathrm{a} 1}^{\mathrm{c}}\right]+\mathrm{E}\left[\mathrm{T}_{\mathrm{s} 2}^{\mathrm{c}}\right]
$$

Journal of Engineering Sciences, Assiut University, Faculty of Engineering, Vol. 41, No. 6, November, 2013, E-mail address: jes@aun.edu.eg 

transmission where source node is at zone III (2 Mbps) and $\mathrm{T}_{\mathrm{a} 2}^{\mathrm{c}}$ is successful time in cooperative transmission where source nodeis at zone IV (1 Mbps).

$$
\begin{aligned}
& \mathrm{E}\left[\mathrm{T}_{\mathrm{a}}^{\mathrm{d}}\right]=\sum_{\mathrm{j}=1}^{4} \mathrm{~T}_{\mathrm{a}, \mathrm{j}}^{\mathrm{d}} \sum_{\mathrm{k}=1}^{\mathrm{N}_{\mathrm{d}}^{\mathrm{d}}} \mathrm{P}_{\mathrm{a}, \mathrm{k}}\left(1-\mathrm{P}_{\mathrm{c}, \mathrm{k}}\right) \\
& \mathrm{E}\left[\mathrm{T}_{\mathrm{S} 1}^{\mathrm{c}}\right]=\sum_{\mathrm{i}=1}^{3} \sum_{\mathrm{j}=1}^{3}\left[\sum_{\mathrm{k}=1}^{\mathrm{N} 4 \mathrm{i}, \mathrm{j} \mathrm{j}} \mathrm{T}_{\mathrm{s}, \mathrm{k}}^{\mathrm{c}} \mathrm{P}_{\mathrm{a}, \mathrm{k}}\left(1-\mathrm{P}_{\mathrm{c}, \mathrm{k}}\right)\right], \text { at } \ell=3 \mathrm{j} \neq 3 \\
& \mathrm{E}\left[\mathrm{T}_{\mathrm{S} 2}^{\mathrm{c}}\right]=\sum_{\mathrm{i}=1}^{2} \sum_{\mathrm{j}=1}^{2}\left[\sum_{\mathrm{k}=1}^{\mathrm{N} 3(\mathrm{~d}, \mathrm{j}]} \mathrm{T}_{\mathrm{s}, \mathrm{k}}^{\mathrm{c}} \mathrm{P}_{\mathrm{a}, \mathrm{k}}\left(1-\mathrm{P}_{\mathrm{c}, \mathrm{k}}\right)\right]
\end{aligned}
$$

where, $[\mathrm{x}]$ is the smallest integer larger than $\mathrm{x} .{ }^{\mathrm{I}(\mathrm{x})}$ is 1 if $\mathrm{x}$ is true, and is 0 otherwise and $\mathrm{P}_{\mathrm{a}, \mathrm{k}}$ is the successful probability for node $\mathrm{k}$.

$$
\begin{aligned}
& E[P L]=8 L_{a} \sum_{i=1}^{4} \sum_{j=1}^{N_{i}^{d}} P_{a, j}\left(1-P_{c, j}\right)+8(L s+L r)\left[\sum_{i=1}^{3} \sum_{j=1}^{3} \sum_{k=1}^{N A(i, j)} P_{a, k}\left(1-P_{c, k}\right)\right. \\
& \left.+\sum_{i=1}^{2} \sum_{j=1}^{2} \sum_{k=1}^{N 3(i, j)} P_{a, k}\left(1-P_{c_{i} k}\right)\right]
\end{aligned}
$$

\section{3. Delay}

The average packet delay is the time interval between two successful transmissions at a node. If the packet is discarded because it has reached retry limit, the delay for this packet will not be included in the computing of the average delay. Let $\mathrm{D}_{i} \mathrm{~g}(\mathrm{i}=1,2, \ldots \ldots, \mathrm{N})$ denote a random variable representing a packet delay of the intended node $\mathrm{i}$. Thus, the average packet delay $E\left[D_{i}\right]$ is expressed as follows:

$\mathrm{E}\left[\mathrm{D}_{\mathrm{i}}\right]=\mathrm{E}\left[\mathrm{D}_{\mathrm{b}, \mathrm{i}}\right]+\mathrm{E}\left[\mathrm{D}_{\mathrm{c}, \mathrm{i}}\right]+\mathrm{E}\left[\mathrm{D}_{\mathrm{a}, \mathrm{i}}\right]$

where $E\left[D_{b i j}\right], E\left[D_{c, i}\right]$, and $E\left[D_{s, i}\right]$ stand for the average delay during decreasing the backoff counter, the average delay due to a collision transmission, and the average delay of a successful transmission, respectively. These average delay values are calculated as follows:

$$
\begin{aligned}
& \mathrm{E}\left[\mathrm{D}_{\mathrm{b}, \mathrm{i}}\right]=\sigma \mathrm{N}_{\mathrm{b}, \mathrm{i}} \\
& \mathrm{E}\left[\mathrm{D}_{\mathrm{c}, \mathrm{i}}\right]=\mathrm{N}_{\mathrm{c}, \mathrm{i}} \mathrm{T}_{\mathrm{c}} \\
& \mathrm{E}\left[\mathrm{D}_{\mathrm{a}, \mathrm{i}}\right]=\mathrm{I}\left(\mathrm{i} \in \mathrm{S}^{\mathrm{d}}\right) \mathrm{T}_{\mathrm{a}, \mathrm{i}}^{\mathrm{d}}+\mathrm{I}\left(\mathrm{i} \in \mathrm{S}^{\mathrm{c}}\right) \mathrm{T}_{\mathrm{a}, \mathrm{i}}^{\mathrm{c}}
\end{aligned}
$$

where the average total number of time slots during the backoff (busy) duration

Journal of Engineering Sciences, Assiut University, Faculty of Engineering, Vol. 41, No. 6, November, 2013,E-mail address: jes@aun.edu.eg 
Ahmed Magdy, et al., Modified Cooperative Access with Relay's Data (MCARD) Protocol, pp. 2231 - 2243

$\mathrm{N}_{\mathrm{b}, \mathrm{i}}=\sum_{\mathrm{j}=0}^{\mathrm{m}=0} \frac{\mathrm{P}_{\mathrm{c}, \mathrm{i}}^{\mathrm{j}}\left(1-\mathrm{P}_{\mathrm{ci}} \mathrm{i}\right)}{1-\mathrm{P}_{\mathrm{c}, \mathrm{i}}^{\mathrm{m}+1}} \sum_{\mathrm{z}=0}^{\mathrm{j}} \frac{\mathrm{W}_{\mathrm{K}}-1}{2} \quad \mathrm{i}=1,2, \ldots \ldots, \mathrm{N}$

The average total number of time slots during the collision transmission

$\mathrm{N}_{\mathrm{c}, \mathrm{i}}=\sum_{\mathrm{j}=0}^{\mathrm{m}} \frac{\mathrm{j}_{\mathrm{c}, \mathrm{i}}^{\mathrm{j}}\left(1-\mathrm{P}_{\mathrm{c}, \mathrm{i}}\right)}{1-\mathrm{P}_{\mathrm{c}, \mathrm{i} i}^{\mathrm{m}+1}} \frac{\mathrm{P}_{\mathrm{c}, \mathrm{i}}}{\mathrm{P}_{\mathrm{c}}}$

Therefore, the total average delay of the network is calculated as follows:

$$
\mathrm{E}\left[\mathrm{D}_{\mathrm{t}}\right]=\frac{1}{\mathrm{~N}} \sum_{\mathrm{i}=1}^{\mathrm{N}} \mathrm{E}\left[\mathrm{D}_{\mathrm{t}}\right]
$$

\section{Analytical and Simulation Results}

To validate the above analysis, a proposed scenario with a desired angle from source node to the relay node is 600 . While the desired angles of the relay to both the source and $\mathrm{AP}$ are $240 \mathrm{o}$ and $300 \mathrm{o}$, respectively. The UCA structure consists of twelve isotropic elementsin both source and relay nodes. Fig.7 shows the array beam-forming synthesized using the GSA [23] with a probe size of 50 and maximum iterations of 1000 to optimize the antenna array feedings. As shown in Fig. 7a, the source antenna array maximizes the main lobe towards the desired angle towards the relay node. While Fig. $7 \mathrm{~b}$ shows the beam-pattern of the relay node towards the source and AP.

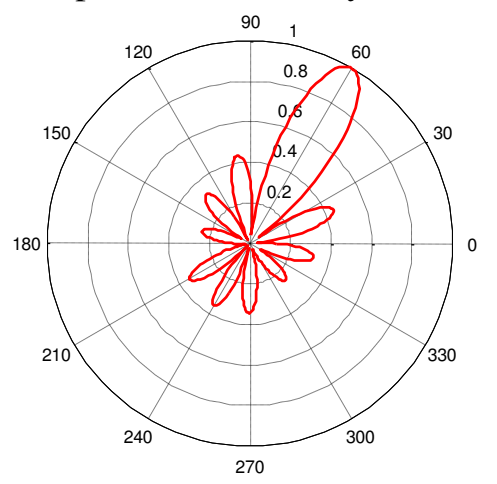

(a) Relay beamforming pattern

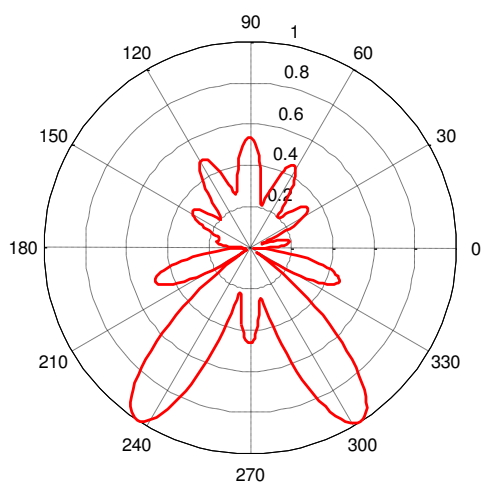

(b) Relay beamforming pattern

Fig. 7. Antenna array beam-pattern from source to relay

The parameters used in simulation and analysis are set to the default values specified in IEEE $802.11 \mathrm{~b}$ standard which are summarized in Table 1.

The MCARD protocol is performed and evaluated for nodes with different data-rates. Specifically, the distances of 50m, 65m, 75m and $100 \mathrm{~m}$ are the thresholds of $11 \mathrm{Mbps}$, $5.5 \mathrm{Mbps}, 2 \mathrm{Mbps}$ and $1 \mathrm{Mbps}$, respectively. The packets arrive in the network according to the Poisson distribution, and the traffic is uniformly distributed across all the nodes in the network.

Journal of Engineering Sciences, Assiut University, Faculty of Engineering, Vol. 41, No. 6, November, 2013,E-mail address: jes@aun.edu.eg 
Ahmed Magdy, et al., Modified Cooperative Access with Relay's Data (MCARD) Protocol, pp. 2231 - 2243

\section{Table 1.}

Simulation parameters

\begin{tabular}{|c|c|c|c|c|c|}
\hline Parameter & Value & Parameter & Value & Parameter & Value \\
\hline Mac header & 272 bits & Slot time & $20 \mu \mathrm{s}$ & $\mathrm{CW}_{\min }$ & 31 slots \\
\hline PHY header & 192 bits & SIFS & $10 \mu \mathrm{s}$ & $\mathrm{CW}_{\max }$ & 1023 slots \\
\hline RTS & 352 bits & DIFS & $50 \mu \mathrm{s}$ & PLCP rate & $1 \mathrm{Mbps}$ \\
\hline CTS & 304 bits & CRTS & 400 bits $\mu \mathrm{s}$ & RRTS & 304 bits \\
\hline ACK & 304 bits & CCTS & 306 bits & CACK & 306 bits \\
\hline
\end{tabular}

It is well known that the packet length has a major effect on the performance of any MAC protocol. Therefore, in Fig. 8, the effect of the packet length on the throughput performance of the 802.11b [2], CoopMAC [18], CARD [20] and MCARD protocols is studied under ideal channel conditions and a fixed number of nodes which is selected to be 30 nodes. The packet size is changed from 400 bytes, at which the RTS/CTS transmission technique can be used in the standard IEEE $802.11 \mathrm{~b}$, to 2000 byte which is approximately the maximum packet length supported by the IEEE $802.11 \mathrm{~b}$. When the packet length increases, the throughput that can be achieved by the $802.11 \mathrm{~b}$, CoopMAC, CARD and MCARD protocols increases. The reason is that the overhead including the PLCP header and control frames is reduced when the packet length increases. The MCARD protocol outperforms the CARD, 802.11b and CoopMAC protocols under different packet lengths from the minimum to the maximum value. The MCARD protocol achieves a higher throughput the MCARD is based on smart antenna array which gives the advantage of transmitting simultaneously for source and relay nodes. The throughput achieved by the MCARD protocol is up to $170 \%$ more than the $802.11 \mathrm{~b}$ and is up to $50 \%$ more than CoopMAC. In addition the throughput of the MCARD is close to the maximum throughput (which is $5 \mathrm{Mbps}$ ) that can be achieved when all of the nodes are running at the maximum transmission rate which is 11 Mbps. Therefore, MCARD protocol achieves both cooperative diversity gain and cooperative multiplexing gain at ideal channel.

The relation between throughput and network size at fixed packet length 1024 is shown in Fig. 9. The 802.11b throughput is approximately constant when network size increase, but in MCARD, CARD and CoopMAC protocols the throughput increases with increasing of network size.

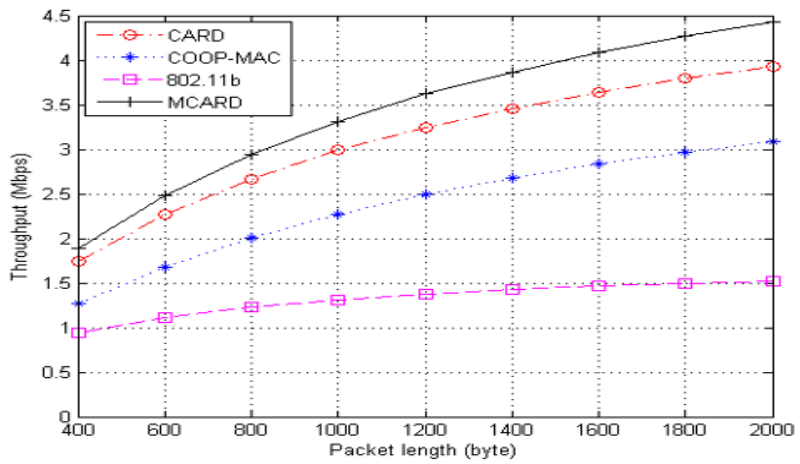

Fig. 8. Throughput versus packet length under ideal channel, $N=30$ nodes.

Journal of Engineering Sciences, Assiut University, Faculty of Engineering, Vol. 41, No. 6, November, 2013,E-mail address: jes@aun.edu.eg 
Ahmed Magdy, et al., Modified Cooperative Access with Relay's Data (MCARD) Protocol, pp. 2231 - 2243

As shown in Fig. 10, the MCARD protocol can achieve total average delay lower than that is achieved by the CARD when the number of nodes is 30 nodes. On the contrary, the CoopMAC protocol achieves only cooperative diversity gain, where the relay node forwards only the information of the source node to the AP.

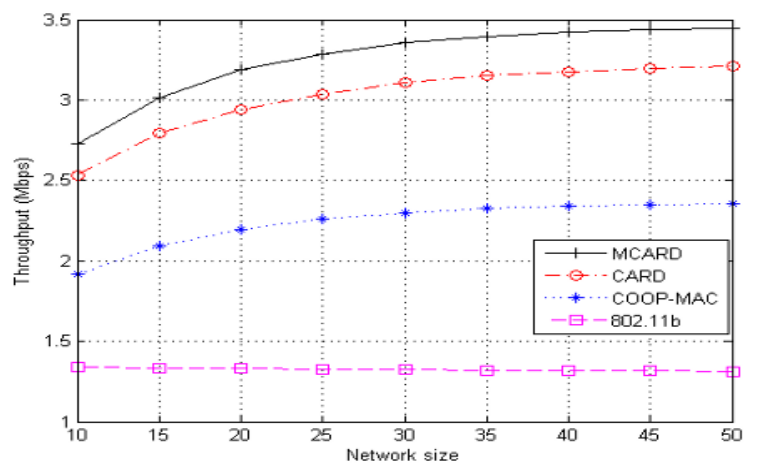

Fig. 9. Throughput vs. network size under ideal channel, L=1024 byte.

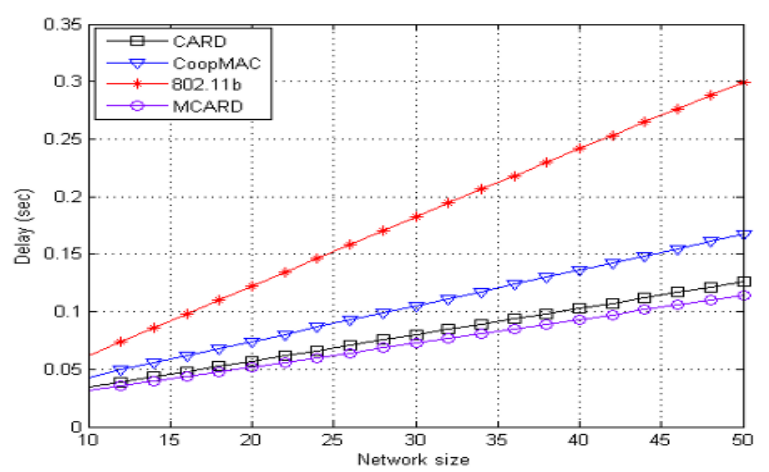

Fig. 10. Service delay vs. network size, $L=1024$ byte

Fig. 11 shows the relationship between total average delay and network size under ideal channel conditions for the different protocols. Total average delay for the MCARD protocol is substantially lower than that for 802.11 b MAC protocol, CoopMAC protocol and CARD protocol for the same packet length.

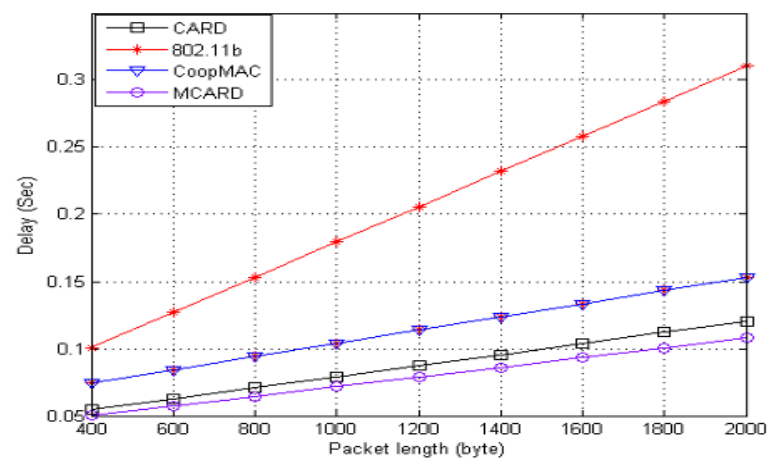

Fig. 11. Service delay vs. packet length, $n=30$ nodes.

Journal of Engineering Sciences, Assiut University, Faculty of Engineering, Vol. 41, No. 6, November, 2013, E-mail address: jes@aun.edu.eg 


\section{Conclusions}

A modified Medium Access Control protocol is proposed in this paper, named Modified Cooperative Access with Relay's Data based on smart antenna (MCARD) for multi-rate WLANs. MCARD uses the best relay node to improve the overall transmission rate for low data-rate nodes. Smart antenna beam forming based on GSA optimization technique is proposed. This design gives the relay node the opportunity to transmit and receive at the same time based on the SDMA technique. In doing so, MCARD provides a novel transmission mechanism for the relay node and therefore can achieve both cooperative diversity gain and multiplexing gain. The MCARD achieves throughput higher than 802.11 by up to $170 \%$, higher than CoopMAC by up to $50 \%$, and higher than CARD approximately by $10 \%$ under ideal channel conditions with varying packet length at fixed number of nodes. Finally, MCARD has lower total average delay than other protocols.

\section{References}

[1] IEEE Std. 802.11-1999, Part 11: Wireless LAN Medium Access Control (MAC) and Physical Layer (PHY) specifications, 1999.

[2] IEEE Std. 802.11b-1999, Part 11: Wireless LAN Medium Access Control (MAC) and Physical Layer (PHY) specifications: High-Speed Physical Layer Extension in the 2.4GHz Band, 1999.

[3] IEEE Std 802.11a-1999, Part 11: Wireless LAN Medium Access Control (MAC) and Physical Layer (PHY) specifications: High Speed Physical Layer in the 5GHz Ban, 1999.

[4] IEEE 802.1 le/D4.0, Draft Supplement to Part 11: Wireless Medium Access Control (MAC) and physical layer (P1119 specifications: Medium Access Control (MAC) Enhancements for Quality of Service (QoS), 2000.

[5] M. Heusse, F. Rousseau, G. Berger-Sabbatel, and A. Duda, "Performance anomaly of 802.11b," in Proc. of IEEE INFOCOM, San Francisco, USA, March-April 2003.

[6] J. N. Laneman and G. W. Wornell, "Distributed space-time coded protocols for exploiting cooperativediversity in wireless networks," IEEE Trans. Inform. Theory, vol. 49, pp. 24152425, Oct. 2003.

[7] J. N. Laneman, D. N. C. Tse, and G. W. Wornel, "Cooperative diversity in wireless networks: efficient protocols and outage behavior," IEEE Trans. Inf. Theory, vol. 50, no. 12, pp. $3062-$ 3080, Dec 2004.

[8] A. Sendonaris, E. Erkip, and B. Aazhang, "User cooperation diversity- Part I: system description," IEEE Trans. Comm., vol. 51, pp. 1927-1938, Nov. 2003.

[9] A. Sendonaris, E. Erkip, and B. Aazhang, "User cooperation diversity- Part II: implementation aspects and performance analysis," IEEE Trans. Comm., vol. 51, pp. 19391948, Nov. 2003.

[10] T. E. Hunter and A. Nosratinia, "Cooperation diversity through coding," in Proc. IEEE ISIT, Laussane,Switzerland, July 2002, p. 220.

[11] M. Janani, A. Hedayat, T. E. Hunter, and A. Nostratinia, "Coded cooperation in wireless communications: space-time transmission and iterative decoding," IEEE Trans. Signal Processing, vol. 52, no. 1, pp. 362-371, Feb. 2004.

[12] T. Hunter and A. Nosratinia, "Coded cooperation under slow fading, fast fading and power control," AsilomarConferencce on Signals, Systems, and Computers, Nov. 2002.

[13] T. Hunter, S. Sanayei, and A. Nosratinia, "Outage analysis of coded cooperation," IEEE Trans. Info. Theory, vol. 52, pp. 375-391, Feb. 2006.

[14] G. Holland, N. Vaidya, and P. Bahl, "A Rate-Adaptive MAC Protocol for Multihop Wireless Networks,” in Proc. ACM Mobicom Conf., July 2001, pp. 236-251.

Journal of Engineering Sciences, Assiut University, Faculty of Engineering, Vol. 41, No. 6, November, 2013,E-mail address: jes@aun.edu.eg 
Ahmed Magdy, et al., Modified Cooperative Access with Relay's Data (MCARD) Protocol, pp. 2231 - 2243

[15] B. Sadeghi, V. Kanodia, A. Sabharwal, and E. Knightly, "OAR: An Opportunistic Autorate Media Access Protocol for Ad Hoc Networks," Wireless Networks, vol. 11, no. 1-2, pp. 39-53, 2005.

[16] H. Zhu and G. Cao, "On Improving the Performance of IEEE 802.11 with Relay-Enabled PCF," Mobile Networking and Applications (MONET), vol. 9, pp. 423-434, 2004.

[17] — "rDCF: A Relay-Enabled Medium Access Control Protocol for Wireless Ad Hoc Networks," IEEE Transactions on Mobile Computing, vol. 5, no. 9, pp. 1201-1213, Sept. 2006.

[18] P. Liu, Z. Tao, S. Narayanan, T. Korakis, and S. S. Panwar, "CoopMAC: A Cooperative MAC for Wireless LANs," IEEE Journal on Selected Areas in Communications, vol. 25, no. 2, pp. 340-354, February 2007.

[19] S. Shankar, C. Chou, and M. Ghosh, "Cooperative communication MAC (CMAC) - a new MAC protocol for next generation wireless LANs," Proc. of IEEE WirelessCom, June 2005.

[20] S. G. Sayed, Y. Yang, and H. Hu, "CARD: cooperative access with relays data for multi-rate wireless local area networks, "ICC'09 Proceedings of the 2009 IEEE international conference on Communications, pp. 4616-4621, 2009.

[21] S. G. Sayed, Y. Yang, and J. Xu, "BTAC: A Busy Tone Based Cooperative MAC Protocol for Wireless Local Area Networks," Mobile Networks and Applications, vol. 16, pp. 4-16, 2011.

[22] P.H. Lehne and M. Pettersen, An overview of smart antenna technology for mobile communications systems, IEEE Commun Surveys Tutorials 2, pp. 2-13, 1999.

[23] M. Chryssomallis, Smart antennas, IEEE Antennas Propag Mag., vol. 42, 129-136, 2000.

[24] D.W. Boeringer and D.H. Werner, Particle swarm optimization versus genetic algorithms for phased array synthesis, IEEE Trans Antennas Propag., vol. 52, 771-779, 2004.

[25] K. R. Mahmoud, M. El-Adawy, R. Bansal, S. H. Zainud-Deen, and S. M. M. Ibrahem, "Analysis of Uniform Circular Arrays for Adaptive Beamforming Applications Using Particle Swarm Optimization Algorithm," Int. J. of RF and Microwave Computed Aided Eng., vol. 18, pp. 42-52, 2008.

[26] E. Rashedi, H. Nezamabadi-Pour, and S. Saryazdi, "GSA: A Gravitational Search Algorithm,” Information Sciences, Vol. 179, No. 13, pp. 2232-2248, 2009.

[27] A. Chatterjee, G. K. Mahanti, and N. Pathak, "Comparative performance of gravitational search algorithm and modified particle swarm optimization algorithm for synthesis of thinned scanned concentric ring array antenna," Progress In Electromagnetics Research B, Vol. 25, pp. 331-348, 2010.

[28] P. Ioannides and C.A. Balanis, "Uniform circular and rectangular arrays for adaptive beamforming applications,” IEEE Antennas Wireless PropagLett., vol. 4, 351-354, 2005.

\section{الولوج التعاوني المعدل مع بيانات النقطة البينيه باستخدام الهوائيات الأكية}
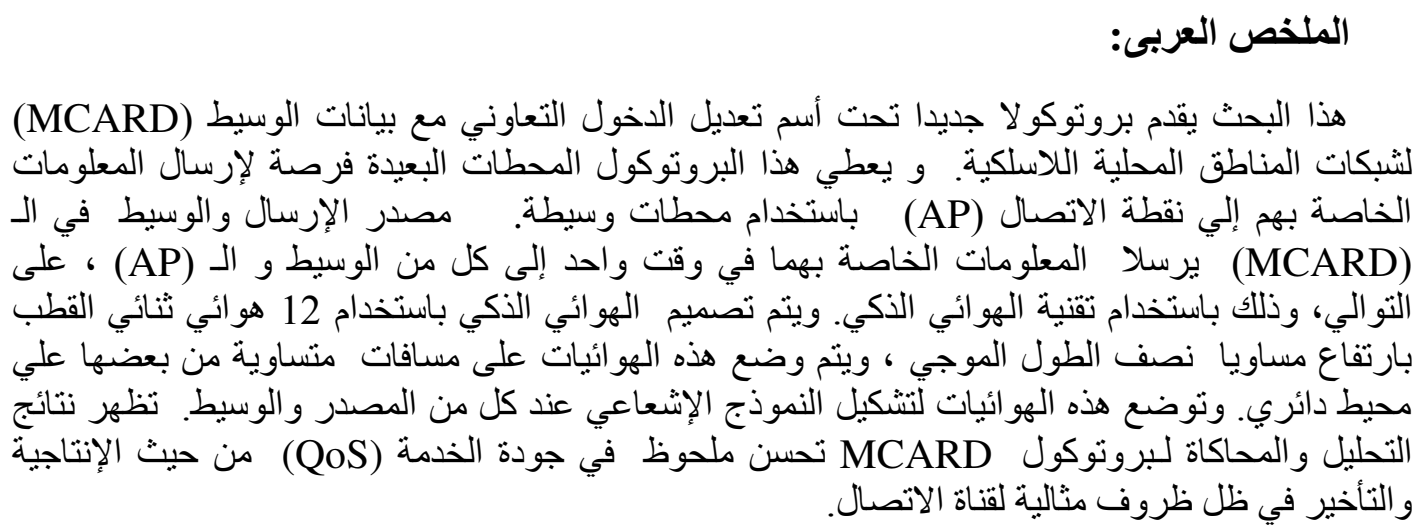

Journal of Engineering Sciences, Assiut University, Faculty of Engineering, Vol. 41, No. 6, November, 2013, E-mail address: jes@aun.edu.eg 